\title{
Expression level of Ubc9 protein in rat tissues
}

\author{
Filip Gołębiowski ${ }^{1}$, Aneta Szulc ${ }^{1}$, Monika Sakowicz ${ }^{1}$, Andrzej Szutowicz ${ }^{2}$ \\ and Tadeusz Pawełczyk ${ }^{1 凶}$ \\ ${ }^{1}$ Department of Molecular Medicine, and ${ }^{2}$ Department of Laboratory Medicine, \\ Medical University of Gdańsk, 80-211 Gdańsk, Poland
}

Received: 27 September, 2003; revised: 28 November, 2003; accepted: 09 December, 2003

Key words: recombinant protein, Ubc9, tissue distribution, rat

\begin{abstract}
Ubc9 is a homologue of the $\mathrm{E} 2$ ubiquitin conjugating enzyme and participates in the covalent linking of SUMO-1 molecule to the target protein. In this report we describe a simple and efficient method for obtaining pure human recombinant Ubc9 protein. The purified Ubc9 retained its native structure and was fully active in an in vitro sumoylation assay with the promyelocytic leukaemia (PML) peptide as a substrate. In order to better understand the physiology of Ubc9 protein we examined its levels in several rat tissues. Immunoblot analyses performed on tissue extracts revealed quantitative and qualitative differences in the expression pattern of Ubc9. The Ubc9 protein was present at a high level in spleen and lung. Moderate level of Ubc9 was detected in kidney and liver. Low amount of Ubc9 was observed in brain, whereas the $18 \mathrm{kDa}$ band of Ubc9 was barely visible or absent in heart and skeletal muscle. In heart and muscle extracts the Ubc9 antibodies recognized a $38 \mathrm{kDa}$ protein band. This band was not visible in extracts of other rat tissues. A comparison of the relative levels of Ubc9 mRNA and protein indicated that the overall expression level of Ubc9 was the highest in spleen and lung. In spleen, lung, kidney, brain, liver and heart there was a good correlation between the $18 \mathrm{kDa}$ protein and Ubc9 mRNA levels. In skeletal muscle the Ubc9 mRNA level was unproportionally high comparing to the level of the $18 \mathrm{kDa}$ protein.

The presented data indicate that in the rat the expression of the Ubc9 protein appears to have some degree of tissue specificity.
\end{abstract}

Sumoylation is a post-translational modification of proteins involving formation of an isopeptide bond between the carboxyl terminus of SUMO-1 (also known as UBL1, sentrin,

\footnotetext{
${ }^{\text {This }}$ work was supported by the State Committee for Scientific Research (KBN, Poland) grant No. 6 P05A 03720 to T.P.

${ }^{{ }}$To whom correspondence should be addressed; tel.: (48 58) 349 2750; fax: (48 58) 349 2759; e-mail: tkpaw@amg.gda.pl
}

Abbreviations: GST, glutathione-S-transferase; PBS, phosphate-buffered saline; TBS, Tris-buffered saline. 
PIC1, SMTP3 or GMP1) and a lysine side chain of the target protein (Müller et al., 2001; Tatham et al., 2003). The SUMO-1 pathway involves ATP-dependent SUMO-1 activation catalyzed by the heterodimeric SUMO-1 activating enzyme (SAE1/SAE2), transfer of SUMO-1 to the SUMO-1-conjugating enzyme Ubc9 in a transesterification reaction and the final transfer of SUMO-1 from the SUMO-1-Ubc9 complex to the target protein. Covalent attachment of SUMO-1, unlike ubiquitination, does not result in degradation of the modified proteins, but enhances their stability or affects their subcellular compartmentalization (Matunis et al., 1996; Desterro et al., 1998; Kang et al., 2003). Modification of proteins by SUMO-1 has been shown to be involved in multiple vital cellular processes, including DNA repair and replication, nuclear transport, oncogenesis, response to viral infection and the inflammation (Mao et al., 2000; Mahajan et al., 1997; Rodriguez et al., 1999; Hofmann et al., 2000; Baier et al., 2003).

The Ubc9 protein has been reported to associate with a large variety of cellular proteins including the putative tumor suppressor protein Fhit (Shi et al., 2000). Ubc9 may modulate the activity of the interacting protein directly or by catalyzing the covalent attachment of SUMO-1. Direct activation of androgen receptor (Poukka et al., 1999) and abrogation of TEL (product of an E-26 transforming specific (ETS)-related gene) repressor activity (Chakrabarti et al., 1999) by interacting Ubc9 protein have been reported.

To date little is known about the physiology of the Ubc9 protein in spite of the intense research being conducted on the sumoylation process. As the first step toward understanding of the physiological role of Ubc9 we have examined the expression levels of Ubc9 in several rat tissues. In order to study the interaction of Ubc9 with other proteins we also developed a simple and efficient method for obtaining pure human recombinant Ubc9 protein.

\section{MATERIALS AND METHODS}

4-(2-Aminoethyl)-benzenesulfonyl fluoride hydrochloride (Pefabloc SC) was from Roche Applied Science (Mannhein, Germany). Escherichia coli BL21(DE3), and DH5 $\alpha$, oligo(dT), and dNTPs were from Invitrogen (Garlsbad, CA, U.S.A.). All primers were from Integrated DNA Technologies, Inc. (Coralville, IA, U.S.A.). Total RNA Prep Plus Kit, Plasmid Miniprep Plus and DNA Clean-Up Kit were from A\&A Biotechnology (Gdańsk, Poland). Moloney murine leukemia virus reverse transcriptase (MMLV-RT), and Tfl DNA polymerase were from Epicentre Technologies (Madison, WI, U.S.A.). RNasin was from Promega (Madison, WI, U.S.A.). BamHI and EcoRI were from Fermentas $\mathrm{AB}$ (Vilnius, Lithuania). Leupeptin, isopropyl $\beta$-D-thiogalactopyranoside, ampicillin, alkaline phosphataseconjugated goat anti-rabbit IgG, 5-bromo-4chloro-3-indoyl phosphate, and Nitro Blue Tetrazolium were from Sigma- Aldrich Sp. z o.o. (Poznań, Poland). Transfer Membrane was from Millipore Corp. (Bedford, MA, U.S.A.). Recombinant SUMO-1, GST-PML fusion peptide and SAE1/SAE2 activating proteins were obtained from Dr. Ronald T. Hay from the Institute of Biomolecular Sciences at University of St. Andrews in Scotland.

RNA extraction and reverse transcription. Total RNA was extracted from human blood cells or from rat tissues with the use of Total RNA Prep Plus Kit and stored at $-40^{\circ} \mathrm{C}$. Reverse transcription was performed in $20 \mu \mathrm{l}$ final volume of $50 \mathrm{mM}$ Tris $/ \mathrm{HCl}, \mathrm{pH} 8.3,75$ $\mathrm{mM} \mathrm{KCl}, 10 \mathrm{mM} \mathrm{\textrm {MCl } _ { 2 }}, 10 \mathrm{mM}$ DTT, $1 \mathrm{mM}$ dNTPs, $500 \mathrm{ng}$ oligo(dT), $12.5 \mathrm{U}$ of reverse transcriptase (MMLV-RT), $10 \mathrm{U}$ of RNasin, and $1-3 \mu \mathrm{g}$ of RNA. The reactions were incubated for $10 \mathrm{~min}$ at $22^{\circ} \mathrm{C}, 90 \mathrm{~min}$ at $37^{\circ} \mathrm{C}$ and 5 min at $95^{\circ} \mathrm{C}$.

Multiplex PCR. In order to assess the level of the UBC9 gene transcript, we performed multiplex PCR with $\beta$-actin mRNA as a reference template. For UBC9 amplification the primers UBC24, CACCCATTTGGATCCGTG- 
GC (forward) and UBC119, GGAGTACGGGGAATTCTAA ATGAACC (reverse) were used. This defines a DNA fragment of 310 base pairs. The primers were based on the rat cDNA sequence (Gen Bank, Accession No. NW 047334). Primers for $\beta$-actin amplification were as described (Sakowicz et al., 2001), and the product was 511 base pairs long. The reaction mixture contained $50 \mathrm{mM}$ Tris $/ \mathrm{HCl}$, $\mathrm{pH}$ 9.0, $20 \mathrm{mM}$ ammonium sulfate, $300 \mathrm{ng}$ of template, $0.40 \mu \mathrm{M}$ each of the 5 ' and 3 ' primers, $0.375 \mathrm{mM}$ of each dNTP, $3.75 \mathrm{mM} \mathrm{MgCl}_{2}$ and $0.75 \mathrm{U}$ of Tth DNA polymerase. The PCR for $\beta$-actin and Ubc 9 consisted of an initial denaturation at $95^{\circ} \mathrm{C}$ for $3 \mathrm{~min}$ and 34 cycles of $30 \mathrm{~s}$ at $95^{\circ} \mathrm{C}, 30 \mathrm{~s}$ at $57^{\circ} \mathrm{C}, 30 \mathrm{~s}$ at $72^{\circ} \mathrm{C}$, and a final extension of $10 \mathrm{~min}$ at $72^{\circ} \mathrm{C}$ amplification.

The PCR reactions were performed in an Eppendorf-Mastercycler. The PCR products were separated by agarose gel electrophoresis and assessed by quantitation of ethidium bromide-stained bands with the use of the Gel Doc 2000 system (Bio-Rad). The relative amounts $\left(\mathrm{OD} / \mathrm{mm}^{2}\right)$ of both amplified transcripts were compared using the computer program Quantity One (Bio-Rad).

Cloning of the UBC9 gene. Unless otherwise indicated, the recombinant DNA methods used were those of Sambrook et al. (1989). In order to obtain cDNA for hUbc9 we run a PCR reaction with the primers PCU-1 GGATCCTTGAACATGGCGGGGATC (forward) and PCU-3, AGCAGTCTTCCTTCCTTAAGCAA (reverse), which introduced restriction enzyme cleavage sites (underlined) for $B a m H I$ and EcoRI, respectively. The primers were based on the human cDNA sequence (National Center for Biotechnology Information, accession No. U31933). The PCR reaction was performed in $20 \mu \mathrm{l}$ final volume in $50 \mathrm{mM}$ Tris/ $\mathrm{HCl}, \mathrm{pH}$ 7.5, $20 \mathrm{mM}$ ammonium sulfate, $2.5 \mathrm{mM} \mathrm{MgCl}_{2}, 0.25 \mathrm{mM}$ dNTPs, $1 \mathrm{U}$ of Tfl DNA polymerase, $0.5 \mu \mathrm{M}$ primers and 1-2 $\mu \mathrm{g}$ of human blood cell cDNA. The PCR consisted of an initial denaturation at $94^{\circ} \mathrm{C}$ for $3 \mathrm{~min}$ and 35 cycles of $30 \mathrm{~s}$ at $94^{\circ} \mathrm{C}, 30 \mathrm{~s}$ at $59^{\circ} \mathrm{C}, 45 \mathrm{~s}$ at $72^{\circ} \mathrm{C}$, and a final extension of 10 min at $72^{\circ} \mathrm{C}$. The PCR product (529 bp) was then cut with appropriate enzymes and ligated into the unique BamHI and EcoRI sites in pGEX-TKG vector (Kowara et al., 1999). The pGEX-TKG/UBC9 plasmid was produced in $E$. coli $\mathrm{DH} 5 \alpha$ cells. The cloned cDNA was sequenced and was confirmed to be complete hUbc9 coding cDNA.

Cell growth and expression of hUbc9. pGEX-TKG/UBC9 was used for the expression of hUbc9 as a fusion protein with Schistosoma japonicum glutathione-S-transferase (GST) at the amino-terminus. E. coli BL21(DE3) cells were transformed with the above-mentioned plasmid and colonies were grown on agar plates containing $100 \mu \mathrm{g} / \mathrm{ml}$ ampicillin. Picked colonies were grown overnight at $37^{\circ} \mathrm{C}$ in ampicillin-containing LuriaBertani (LB) medium and $1 \mathrm{ml}$ of this culture was inoculated into $1 \mathrm{l}$ of fresh medium, and incubated at $37^{\circ} \mathrm{C}$ to an absorbance of $0.7-0.8$ (measured at $600 \mathrm{~nm}$ ). Expression of the GST-hUbc9 protein was induced by the addition of $1 \mathrm{mM}$ isopropyl $\beta$-D-thiogalactopyranoside (IPTG). Following induction, the cells were grown for $3 \mathrm{~h}$ and harvested by centrifugation.

Purification of hUbc9. All steps were done at $4{ }^{\circ} \mathrm{C}$. Cell pellet from $1 \mathrm{l}$ culture was suspended in $40 \mathrm{ml}$ of potassium phosphate-buffered saline (PBS), $\mathrm{pH} 7.4,1 \mathrm{mM}$ EDTA, 5 $\mathrm{mM} \beta$-mercaptoethanol, $10 \mu \mathrm{g} / \mathrm{ml}$ leupeptin, $0.2 \mathrm{mM}$ Pefablock SC, $1 \mathrm{mM}$ benzamidine (buffer A), placed on powdered dry ice and sonicated. The crude cell extract was clarified by centrifugation at $50000 \times \boldsymbol{g}$ for $30 \mathrm{~min}$. The obtained supernatant was supplemented with Triton X-100 to a final concentration of $1 \%$ and passed through a $7 \mathrm{ml}$ agarose-glutathione column preequilibrated with buffer $\mathrm{A}$ containing 1\% Triton X-100 (buffer A1). The column was washed successively with $200 \mathrm{ml}$ of buffer A1 containing $1 \mathrm{mM}$ ATP, $10 \mathrm{mM}$ $\mathrm{MgCl}_{2}$, and then with $1 \mathrm{l}$ of Tris-buffered saline (TBS), $\mathrm{pH}$ 8.0, $1 \mathrm{mM}$ EDTA, $1 \mathrm{mM}$ DTT, $10 \mu \mathrm{g} / \mathrm{ml}$ leupeptin, $0.2 \mathrm{mM}$ Pefablock SC, 
$1 \mathrm{mM}$ benzamidine. Finally, the GST-hUbc9 protein was eluted from the column with 10 $\mathrm{ml}$ of buffer TBS, $\mathrm{pH}$ 8.0, containing $5 \mathrm{mM}$ glutathione. Fractions containing high protein concentration were combined, desalted on Sephadex G-25 M (Pharmacia columns PD-10) previously equilibrated with PBS, $\mathrm{pH}$ 7.4, $2.5 \mathrm{mM} \mathrm{CaCl}_{2}$. The desalted solution of GST-hUbc9 (4-6 mg) was incubated with thrombin (100 $\mathrm{U})$ at $4^{\circ} \mathrm{C}$ for $6-8 \mathrm{~h}$. Then the solution was passed successively through a 3 $\mathrm{ml}$ agarose-glutathione column, and agarosebenzamidine column. Cleaved hUbc9 protein was dialyzed to PBS, pH 7.4.

SUMO-1 conjugation assay. The conjugation assay was performed using the PML peptide (PRKVIKMESEE) fused to GST (GSTPML) as a substrate. The reaction mixture $(10 \mu \mathrm{l})$ contained $120 \mathrm{ng}$ SAE1/SAE2, $2 \mu \mathrm{g}$ [ ${ }^{125}$ I]-SUMO-1( $\left.\Delta 98-101\right), 200 \mathrm{ng}$ Ubc9, $600 \mathrm{ng}$ GST-PML, $50 \mathrm{mM}$ Tris/HCl, pH 7.5 and an ATP-regenerating system $\left(5 \mathrm{mM} \mathrm{MgCl}_{2}\right.$, $2 \mathrm{mM}$ ATP, $10 \mathrm{mM}$ creatine phosphate, 3.5 $\mathrm{U} / \mathrm{ml}$ of creatine kinase, $0.6 \mathrm{U} / \mathrm{ml}$ of inorganic pyrophosphatase). Reactions were incubated at $37^{\circ} \mathrm{C}$ for $3 \mathrm{~h}$. The reactions were terminated by addition of SDS-sample buffer containing $\beta$-mercaptoethanol and the reaction products were fractionated by SDS/ PAGE (15\%). The dried gels were analysed by phosphor imaging (Fujifilm FLA-3000). Radiolabelling of SUMO-1( $\Delta 98-101)$ with ${ }^{125} \mathrm{I}$ (Amersham) was performed by the chloramine $\mathrm{T}$ method as described by Ciechanover et al. (1980).

Preparation of tissues homogenates. Wistar rats weighing approx. $200 \mathrm{~g}$ were killed by decapitation. The tissue of interest was removed and homogenized in 3 vol. of PBS, pH 7.4, $1 \mathrm{mM}$ Pefabloc SC, using a power-driven pestle. The resulting homogenate was supplemented with $2 \%$ SDS, $75 \mathrm{mM}$ DTT, $10 \%$ glycerol, $0.1 \%$ bromophenol blue and boiled at $100^{\circ} \mathrm{C}$ for $3 \mathrm{~min}$. After centrifugation the supernatant was stored at $4^{\circ} \mathrm{C}$.

Antibodies. Polyclonal antibodies against the hUbc9 protein were generated in rabbits.
Rabbits were subcutaneously injected in the back of the neck with $500 \mu \mathrm{g}$ of purified recombinant hUbc9 protein in Freund's adjuvant followed by three boosts with $300 \mu \mathrm{g}$ of antigen each every 3 weeks. The antibodies were purified by chromatography on a protein A-agarose column.

SDS/PAGE and immunoblotting. Samples (100 $\mu \mathrm{g}$ of protein) were separated by polyacrylamide gel electrophoresis (15\% acrylamide) in the presence of sodium dodecyl sulfate (SDS/PAGE) (Laemmli, 1970) and the protein bands were developed by Coomassie Brilliant Blue staining or electrophoretically transferred to Immobilon poly(vinylidenedifluoride) transfer membrane (Millipore). The membrane was blocked with $3 \%$ bovine albumin (fraction V) in phosphate buffered saline (PBS) with $0.02 \% \mathrm{NaN}_{3}$ and then washed with PBS. The blocked membrane strips were incubated with rabbit anti hUbc9 polyclonal antibodies (dilution 1:10000). Immunostaining was done using alkaline phosphatase-conjugated goat anti- rabbit IgG (dilution $1: 20000$ ), the chromogenic substrate 5-bromo-4-chloro-3-indoyl phosphate and Nitro Blue Tetrazolium. The developed bands were quantified by use of the Gel Doc 2000 system (Bio-Rad) and relative amounts were compared using the computer program Quantity One (Bio-Rad).

Analytical. Protein concentration was determined by the method of Bradford (1976) with bovine serum albumin as a standard. In solutions containing SDS or Triton X-100 protein concentrations were determined by the method of Lowry (1951). DNA and RNA concentrations were determined by measuring the absorbance at $260 \mathrm{~nm}$.

\section{RESULTS}

\section{Expression of GST-hUbc9}

In order to optimize the expression conditions of GST-hUbc9, we cultured the bacterial 
cells at different temperatures and for various periods of time. Expression of GST-hUbc9 at $37^{\circ} \mathrm{C}$ for $3 \mathrm{~h}$ after induction produced 15-20 mg of GST-hUbc9 from $1 \mathrm{l}$ of culture as assessed by densitometric analysis of SDS/PAGE (Fig. 1). Prolongation of the ex-

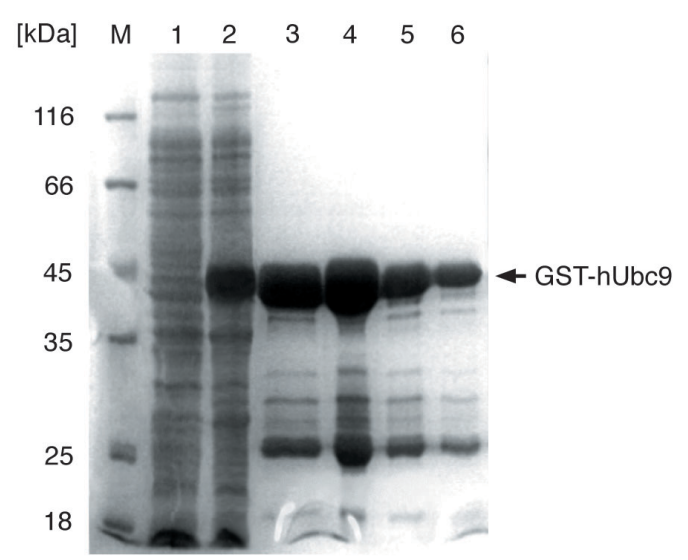

Figure 1. Expression in E. coli and purification of GST-hUbc9 protein on agarose-glutathione.

On individual lanes of $12 \%$ SDS/PAGE were loaded: (1), $50 \mu \mathrm{g}$ of $E$. coli lysate (non-induced); (2), $50 \mu \mathrm{g}$ of lysate of $E$. coli cells induced for $3 \mathrm{~h}$; (3-6) $20 \mu \mathrm{g}$ of protein eluted by $5 \mathrm{mM}$ glutathione from glutathione-agarose column (fractions containing the protein peak). On lane $\mathrm{M}$ molecular mass markers were loaded.

pression time at $37{ }^{\circ} \mathrm{C}$ did not increase the total yield of the protein, whereas the amount of soluble protein (protein recovered in the high-speed supernatant) decreased (not shown). Expression of GST-hUbc9 in E. coli strain BL21(DE3) cultured at $24^{\circ} \mathrm{C}$ for $16 \mathrm{~h}$ or at $18^{\circ} \mathrm{C}$ for $48 \mathrm{~h}$ did not produce a higher amount of this protein. There were no losses in the yield of GST-hUbc9 from bacterial cultures stored on agar plates for up to 30-40 days at $4{ }^{\circ} \mathrm{C}$. Cells stored on agar plates longer than 40 days produced cultures with a lower yield of GST-hUbc9.

\section{Purification of hUbc9}

Usually the process of protein purification started with 4-6 g of $E$. coli cells obtained from $1 \mathrm{l}$ of culture. The purification of GST-hUbc9 on the glutathine-agarose yielded essentially pure protein contaminated mainly by a protein of $27 \mathrm{kDa}$ on SDS/PAGE (Fig. 1). Immunoblot analysis showed that this protein band is recognized by anti-GST polyclonal antibodies (not shown). GST was removed from the GST-hUbc9 fusion protein by incubation with thrombin. Incubation of GST-hUbc9 with thrombin at $4^{\circ} \mathrm{C}$ for $6-8 \mathrm{~h}$ resulted in complete cleavage of the GST tag (Fig. 2). There were no unspecific cleavage

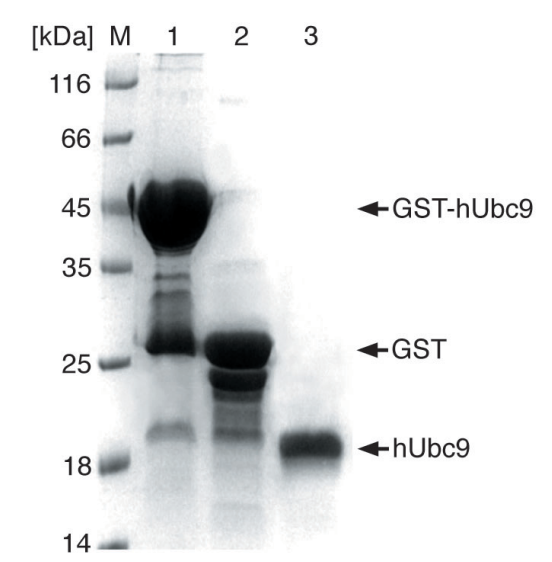

Figure 2. Thrombin cleavage of the GST-hUbc9 protein.

The GST-hUbc9 protein purified on glutathione agarose column (lane 1) was cleaved with thrombin as described under Materials and Methods. Lane 2, GST-hUbc9 protein after $7 \mathrm{~h}$ incubation at $4^{\circ} \mathrm{C}$ with thrombin. Lane 3, recombinant hUbc9 protein purified from thrombin and the cleaved GST. On each lane of $15 \%$ SDS/PAGE (1-3) $20 \mu \mathrm{g}$ of protein was loaded. Lane $\mathrm{M}$, the molecular mass markers.

products. The observed shift in mobility of hUbc9 after the removal of the GST tag was of the order expected from the removal of 27 $\mathrm{kDa}$ protein. Thrombin and the cleaved GST tag were removed by passing successively through an agarose-glutathione column (GST retained), and an agarose-benzamidine column (thrombin retained). The purification yielded 5-10 $\mathrm{mg}$ of electrophoretically pure hUbc9 (Fig. 2).

\section{Catalytic properties of recombinant hUbc9}

In order to characterize the apparent size of native recombinant $\mathrm{hUbc} 9$, the purified pro- 
tein was subjected to a gel filtration on Sephacryl S-100 column calibrated with globular monomeric proteins. Ubc9 eluted slightly faster than the $14.4 \mathrm{kDa}$ lysozyme (not shown). Therefore it may be assumed that the purified Ubc9 protein was present in monomeric form.

Human Ubc9 is a homologue of the ubiquitin-conjugating enzyme E2. In the SUMO-1 pathway Ubc9 transfers activated SUMO-1 to the target protein. In order to examine the enzymatic activity of purified recombinant hUbc9 we performed in vitro SUMO-1 conjugation assay with the promyelocytic leukaemia (PML) peptide as a substrate. The PML peptide (PRKVIKMESEE) contains the consensus sequence $\psi \mathrm{KxE}$ (where $\psi$ is a hydrophobic amino acid and $\mathrm{x}$ is any amino acid) essential for SUMO-1 modification. Analysis of the reaction products separated on SDS/ PAGE indicated that the $39 \mathrm{kDa}$ protein band corresponding to GST-PMLSUMO-1 was only visible when the reaction was run in the presence of recombinant hUbc9 (Fig. 3). This indicates that the obtained hUbc9 protein preserved its native SUMO-1 conjugating activity.

\section{Expression of Ubc9 in rat tissues}

In order to examine Ubc9 expression in various rat tissues we assessed its protein and mRNA level. A comparison of the amino-acid sequences of human (AAC50603) and rat (NP037182) Ubc9 proteins reveals that they are identical in $97 \%$. Therefore, in our experiments we could use polyclonal antibodies against hUbc9. Densitometry analysis of Western blot presented in Fig. 4 indicated that the Ubc9 protein was present at a high level in spleen and was slightly less abundant in lung. A moderate level of Ubc9 was detected in kidney and liver. Low amount of Ubc9 was observed in brain, whereas the 18 $\mathrm{kDa}$ band of Ubc9 was barely visible or absent in heart and skeletal muscle. In contrast, in heart and muscle extracts the anti-Ubc9 polyclonal antibodies recognized a $38 \mathrm{kDa}$ protein band (Fig. 4). This band was not visible in extracts of other rat tissues.

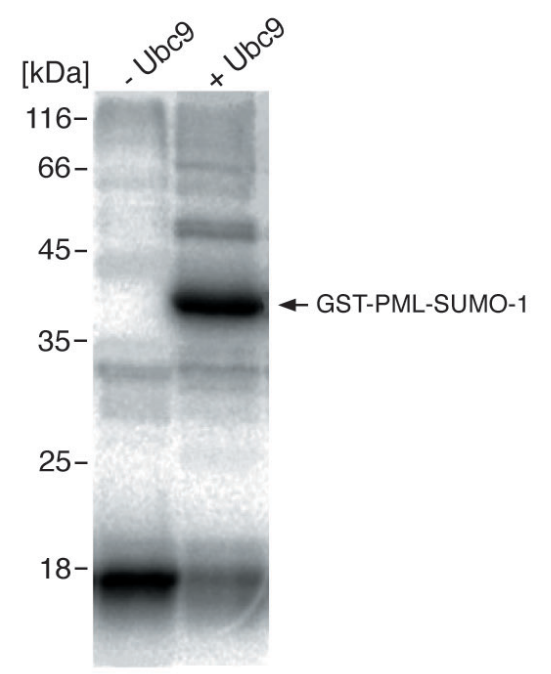

Figure 3. Sumoylation of GST-PML.

Sumoylation of PML peptide (PRKVIKMESEE) fused to GST was performed in the absence (-Ubc9) and in the presence $(+\mathrm{Ubc} 9)$ of purified recombinant human Ubc9 as described in Materials and Methods. The reaction products were fractionated by SDS/PAGE (15\%) and the dried gels were analyzed by phosphor imaging (Fujifilm FLA-3000).

In the rat tissues examined we also evaluated the level of Ubc9 mRNA by multiplex RT-PCR. As a reference transcript we amplified a fragment (511 bp) of $\beta$-actin. The data presented in Fig. 5 indicate that spleen and lung contained similar and the highest level of Ubc9 mRNA. Kidney, liver, brain, and skeletal muscle contained similar levels (about $40 \%$ of that found in the spleen) of Ubc9 mRNA. The lowest level of Ubc9 mRNA was found in the heart. A comparison of the relative level of Ubc9 mRNA and protein indicated that the overall expression level of Ubc9 was the highest in spleen and lung. In spleen, lung, kidney, brain, liver and heart there was a good correlation between the $18 \mathrm{kDa}$ protein and Ubc9 mRNA levels. In skeletal muscle the Ubc9 mRNA level was unproportionally high relative to the level of the $18 \mathrm{kDa}$ protein. 
A
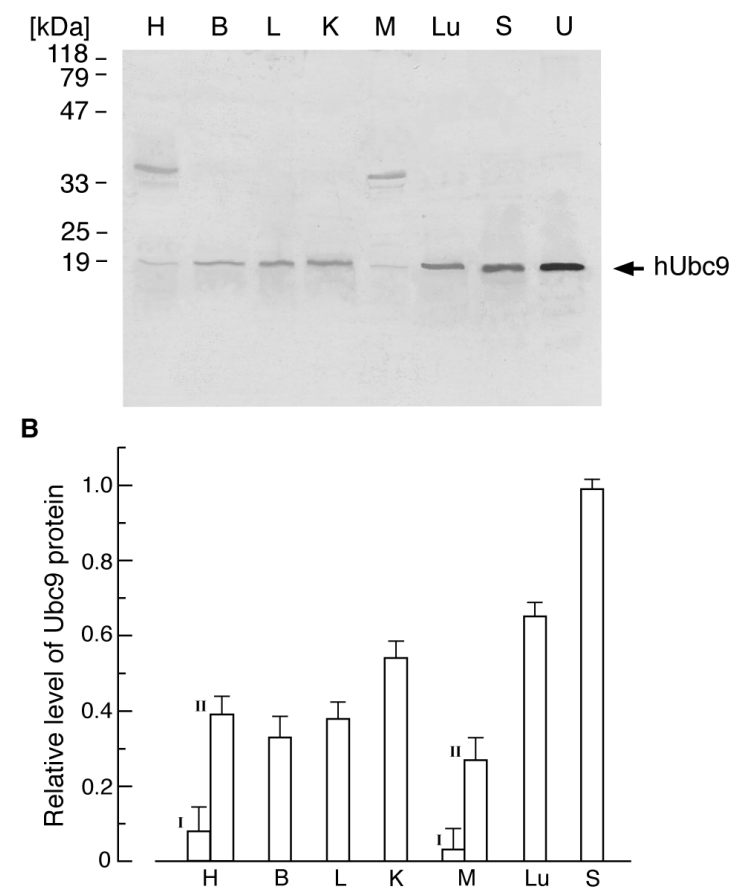

Figure 4. Ubc9 protein levels in rat tissues.

A. Extracts $(100 \mu \mathrm{g})$ of the tissues examined were subjected to $15 \%$ SDS/PAGE and transferred to an Immobilon membrane as described under Materials and Methods. The membranes were immunoblotted with anti-Ubc9 IgG. Lanes H, B, L, K, M, Lu, S refer to extracts of heart, brain, liver, kidney, skeletal muscle, lung, and spleen, respectively. On lane U purified recombinant hUbc9 protein (25 ng) was loaded. The presented blot is representative of those performed on tissue extracts obtained from four different animals. B. The blot shown in part A was scanned and the bands were quantitated. The data are presented as a ratio of the intensity of each protein band to the most intensive band visible in the spleen extract \pm S.D. $(n=4)$. In the case of heart and skeletal muscle the I and II bars represent the protein bands of 18 and $38 \mathrm{kDa}$, respectively.

\section{DISCUSSION}

The expression and purification system described in this contribution allowed the production of large quantities of soluble hUbc9 protein. The obtained GST fusion protein was efficiently cleaved by thrombin owing to the presence of a glycine spacearm prior to the

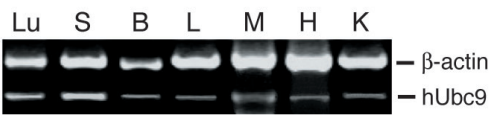

B

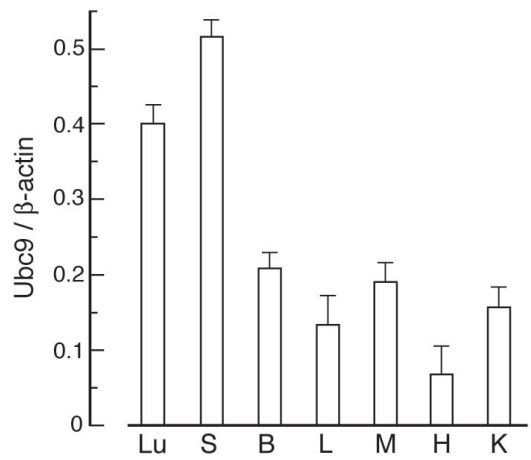

Figure 5. UBC9 gene transcript levels in rat tissues.

The Ubc9 mRNA level was assessed by quantitation of multiplex RT-PCR products as described under Materials and Methods. A. Multiplex RT-PCR products were separated by $2 \%$ agarose gel electrophoresis. Lanes $\mathrm{K}$, $\mathrm{H}, \mathrm{L}, \mathrm{Lu}, \mathrm{M}, \mathrm{S}$, and B refer to the PCR products obtained for kidney, heart, liver, lung, muscle, spleen and brain, respectively. The gel shown is representative of those obtained for three rats. B. Multiplex RT-PCR products were assessed by quantitation of ethidium bromide-stained bands. The ratio of the Ubc9 PCR product $\left(\mathrm{OD} / \mathrm{mm}^{2}\right)$ to the $\beta$-actin PCR product was calculated (Ubc9/ $\beta$-actin). The data are mean \pm S.D. $(n=4)$.

thrombin cleavage site (Hakes \& Dixon, 1992). Digestion of the GST-hUbc9 protein with thrombin leaves only three unrelated amino acids at the N-terminus of hUbc9. These three additional amino acids should not cause any significant disturbances in the structure of the recombinant hUbc9 protein nor affect its function. Functionality of the protein produced was confirmed in an in vitro sumoylation assay (Fig. 5). The assumed physiological role of Ubc9 protein is to transfer the SUMO-1 protein from the SUMO-1- SAE1/SAE2 thioester complex to the target protein substrate. The Ubc9 region that is involved in target protein recognition and interaction has been found to be located in the C-terminal part of the protein (Donghai et al., 2002). It was demonstrated that mutations of Q126, Q130, A131, E132, Y134 and T135 residues significantly affect the Ubc9 interaction with target proteins lead- 
ing to diminished SUMO-1 conjugation. The $\mathrm{N}$-terminal part of Ubc9 forms an $\alpha$-helical structure that is not involved in the binding to the target protein (Donghai et al., 2002), but the interaction of Ubc9 with heterodimeric SAE1/SAE2 was reported to involve the C-terminal part of the N-terminal $\alpha$-helix of Ubc9 (Bencsath et al., 2002).

The data presented in this study show for the first time the distribution of Ubc9 protein and mRNA in rat tissues. Analysis of the immunoblots of the seven rat tissues studied revealed that there are quantitative and qualitative differences among them. The highest content of Ubc9 protein was observed in spleen whereas heart and skeletal muscle exhibited very low levels of Ubc9 (Fig. 4). In the examined tissues the level of the Ubc9 protein correlated well with its mRNA level except for skeletal muscle, where the Ubc9 transcript level was unproportionally high. Such a pattern of Ubc9 expression is different from that obtained for human tissues. The Ubc9 mRNA level was reported to be the highest in human heart and smooth muscle (Wang et al., 1996). In human tissues Northern blot analyses identified UBC9 transcripts of 4.4, 2.4, and $1.3 \mathrm{~kb}$ length. The $1.3 \mathrm{~kb}$ transcript was the main transcript present in all analyzed human tissues, whereas the 2.4 and $4.4 \mathrm{~kb}$ transcripts were mainly expressed in heart and smooth muscle (Wang et al., 1996). Thus, the about $38 \mathrm{kDa}$ protein bands recognized by anti Ubc9 antibodies observed in our studies, could be the products of alternatively spliced transcripts. The Ubc9 protein, beside its enzymatic activity involved in the sumoylation pathway, also displays other activities that are not related to sumoylation. Therefore, changes in Ubc9 expression may affect many cellular processes that are independent of sumoylation including enhancement of the activity of transcription factors and promotion of nuclear translocation (Hahn et al., 1997; Poukka et al., 1999; Chakrabarti et al., 1999; Kurtzman \& Schechter, 2001; Kaul et al., 2002).
Concluding, the presented results indicate that Ubc9 is ubiquitously expressed in rat but at different levels in different tissues. Moreover, our data indicate that the pattern of Ubc9 expression observed in the rat differs significantly from that observed in the human. In order to find out the identity of the 38 $\mathrm{kDa}$ protein recognized by Ubc9 antibodies further experiments are required.

\section{R E F E R E N C E S}

Baier A, Meineckel I, Gay S, Pap T. (2003) Apoptosis in rheumatoid arthritis. Curr Opin Rheumatol.; 15: 274-9.

Bencsath KP, Podgorski MS, Pagala VR, Slaughter CA, Schulman BA. (2002) Identification of multifunctional binding site on Ubc9p required for Smpt3p conjugation. $J$ Biol Chem.; 277: 47938-45.

Bradford MM. (1976) A rapid and sensitive method for the quantitation of microgram quantities of protein utilizing the principle of protein-dye binding. Anal Biochem.; 72: 248-54.

Chakrabarti SR, Sood R, Ganguly S, Bohlander S, Shen Z, Nucifora G. (1999) Modulation of TEL transcription activity by interaction with the ubiquitin-conjugating enzyme UBC9. Proc Natl Acad Sci U S A.; 96: 7467-72.

Ciechanover A, Heller H, Elias S, Haas AL, Hershko A. (1980) ATP-dependent conjugation of reticulocyte proteins with the polypeptide required for protein degradation. Proc Natl Acad Sci U S A.; 77: 1365-8.

Desterro JM, Rodriguez MS, Hay RT. (1998) SUMO-1 modification of $\mathrm{I} \kappa \mathrm{B} \alpha$ inhibits NF- $\kappa \mathrm{B}$ activation. Mol Cell.; 2: 233-9.

Donghai L, Tatham MH, Yu B, Kim S, Hay RT, Chen Y. (2002) Identification of a substrate recognition site on Ubc9. J Biol Chem.; 277: 21740-8.

Golebiowski F, Kowara R, Pawelczyk T. (2001) Distribution of Fhit protein in rat tissues and its intracellular localization. Mol Cell Biochem.; 226: 49-55. 
Hahn SL, Wasylyk B, Criqui-Filipe P, Criqui P. (1997) Modulation of ETS-1 transcriptional activity by huUBC9, a ubiquitin-conjugating enzyme. Oncogene.; 15: 1489-95.

Hakes DJ, Dixon JE. (1992) New vectors for high level expression of recombinant proteins in bacteria. Anal Biochem.; 202: 293-8.

Hofmann H, Floss S, Stamminger T. (2000) Covalent modification of the transactivator protein IE2-p86 of human cytomegalovirus by conjugation to the ubiquitin-homologous proteins SUMO-1 and hSMT3b. J Virol.; 74: 2510-24.

Kang SI, Chang W-J, Cho S-G, Kim IY. (2003) Modification of promyelocytic leukemia zinc finger protein (PLZF) by SUMO-1 conjugation regulates its transcriptional repressor activity. J Biol Chem. (in press).

Kaul S, Blackford JA, Cho S, Simons SS Jr. (2002) Ubc9 is a novel modulator of the induction properties of glucocorticoid receptors. J Biol Chem.; 277: 12541-9.

Kowara R, Gryckiewicz E, Matecki A, Pawelczyk T. (1999) The ultraviolet studies on protein-lipid interaction of a protein kinase $\mathrm{C}-\gamma$ phorbol-binding domain. Acta Biochim Polon.; 46: $405-17$.

Kurtzman AL, Schechter N. (2001) Ubc9 interacts with a nuclear localization signal and mediates nuclear localization of the paired-like homeobox protein $\mathrm{Vsx}$-1 independent of SUMO-1 modification. Proc Natl Acad Sci U A.; 98: 5602-7.

Laemmli UK. (1970) Cleavage of structural proteins during the assembly of the head of bacteriophage T4. Nature.; 227: 680-5.

Lowry OH, Rosebrough NJ, Farr AL, Randall RJ. (1951) Protein measurements with the Folin phenol reagent. J Biol Chem.; 193: 263-73.

Mahajan R, Delphin C, Guan T, Gerace L, Melchior F. (1997) A small ubiquitin-related polypeptide involved in targeting RanGAP1 to nuclear pore complex protein RanBP2. Cell.; 88: 97-107.

Mao Y, Sun M, Desai SD, Liu LF. (2000) SUMO-1 conjugation to topoisomerase I: a possible repair response to topoisomerase-mediated DNA damage. Proc Natl Acad Sci U S A.; 97: 4046-51.

Matunis MJ, Coutavas E, Blobel G. ((1996) A novel ubiquitin-like modification modulates the partitioning of the Ran-GTPase-activating protein RanGAP1 between the cytosol and the nuclear pore complex. J Cell Biol.; 135: 1457-70.

Müller S, Hoege C, Pyrowolakis G, Jentsch S. (2001) SUMO, ubiquitin's mysterious cousin. Mol Cell Biol.; 2: 202-10.

Poukka H, Aarnisalo P, Karvonen U, Palvimo JJ, Janne OA. (1999) Ubc9 interacts with the androgen receptor and activates receptor-dependent transcription. J Biol Chem.; 274: 19441-6.

Rodriguez MS, Desterro JM, Lain S, Midgley CA, Lane DP, Hay RT. (1999) SUMO-1 modification activates the transcriptional response of p53. EMBO J.; 18: 6455-61.

Sakowicz M, Grdeń M, Pawełczyk T. (2001) Expression level of adenosine kinase in rat tissues. Lack of phosphate effect on the enzyme activity. Acta Biochim Polon.; 48: $745-54$.

Sambrook J, Fritsch EF, Maniatis F. (1989) In Molecular cloning: a laboratory manual. 2nd ed. Cold Spring Harbor Laboratory Press, Cold Spring Harbor, NY.

Shi Y, Zou M, Farid NR, Paterson MC. (2000) Association of FHIT (fragile histidine triad), a candidate tumor suppressor gene, with the ubiquitin-conjugating enzyme hUBC9.

Biochem J.; 352: 443-8.

Tatham MH, Kim S, Yu B, Jaffray E, Song J, Zheng J, Rodriguez MS, Hay RT, Chen Y. (2003) Role of an N-terminal site of Ubc9 in SUMO-1, -2 , and -3 binding and conjugation. Biochemistry.; 42: 9959-69.

Wang ZY, Qiu QQ, Seufert W, Taguchi T, Testa JR, Whitmore SA, Callen DF, Welsh D, Shenk T, Deuel TF. (1996) Molecular cloning of the cDNA and chromosome localization of the gene for human ubiquitin-conjugating enzyme 9. J Biol Chem.; 271: 24811-6. 